\title{
INIBIÇÃO DO DESENVOLVIMENTO DE ALEUROCANTHUS WOGLUMI ASHBY (HEMIPTERA: ALEYRODIDAE) POR ASCHERSONIA CF. ALEYRODIS WEBBER (DEUTEROMYCOTINA: HYPHOMYCETES)
}

\author{
M.R. Pena ${ }^{1}$, N.M. da Silva ${ }^{1}$, J.L.S. Bentes ${ }^{1}$, S.B. Alves ${ }^{2}$, \\ E.J.S. Bezerra ${ }^{1}$, J.D. Vendramim ${ }^{2}$, A.L. Lourenção ${ }^{3}$, R.A. Humber ${ }^{4}$
}

${ }^{1}$ Universidade Federal do Amazonas, Departamento de Ciências Fundamentais e Desenvolvimento Agrícola, Av. Gen. Rodrigo Octávio, 3000, CEP 69077-000, Manaus, AM, Brasil. E-mail: marciarpena@yahoo.com.br

\section{RESUMO}

\begin{abstract}
Os insetos hospedeiros do fungo Aschersonia sp. estão restritos às famílias Aleyrodidae e Coccidae, da ordem Hemiptera. Objetivou-se avaliar o efeito, in vitro, desse fungo, nos diferentes estádios de desenvolvimento da mosca-negra-dos-citros, A. woglumi, como potencial agente de controle biológico, através de bioensaios com diferentes concentrações de inóculo do fungo. A melhor eficiência de controle foi constatada em concentrações mais elevadas, a partir de 2,3 x 10 conídios $/ \mathrm{mL}$, revelando-se como um bom agente de controle biológico dessa praga. Embora tenha apresentado crescimento lento no meio de cultura testado, Aschersonia cf. aleyrodis mostrou-se eficiente no controle da mosca-negra-dos-citros. As maiores mortalidades ocorreram nas fases mais jovens de $A$. woglumi como ovo, ninfa 2 e ninfa 1, não havendo diferença estatística entre elas. No estádio de ninfa 4, ocorreu a menor mortalidade. As mortalidades nas fases de ovo, ninfas 1 , 2 e 3, com exceção da ninfa 4, se iniciaram no quarto dia após a inoculação de $A$. cf. aleyrodis, com acmes de mortalidade no $10^{\circ}$ dia.
\end{abstract}

PALAVRAS-CHAVE: Controle biológico, fungo entomopatogênico, praga dos citros.

\section{ABSTRACT}

INIBITIONOFTHEDEVELOPMENTOF ALEUROCANTHUS WOGLUMI ASHBY (HEMIPTERA: ALEYRODIDAE) BY ASCHERSONIACF. ALEYRODIS (DEUTEROMYCOTINA:HYPHOMYCETES). The host insects of the fungus Aschersonia sp. are restricted to the Aleyrodidae and Coccidae families of the Hemiptera order. The present study was aimed at evaluating, through bioessays with different concentrations of the fungi, the effect of this fungus, in-vitro, on different developmental stages of Aleurocanthus woglumi, thus testing it as a potential biological control agent. Aschersonia cf. aleyrodis proved more efficient in the control of A. woglumi at higher concentrations, from $2.3 \times 10^{7}$ conidia/mL, turning out to be a good biological control agent of this pest. Although it presented slow growth in the culture medium tested, Aschersonia cf. aleyrodis proved to be efficient in the control of citrus blackfly. The highest mortalities occurred in the youngest stages of $A$. woglumi as an egg, and at the second and first nymph stages, there being no statistical difference between them. The lowest mortality occurred at the fourth nymph stage. The mortalities at the egg stage, and at the first, second and third nymph stages (but not the fourth), began on the fourth day after $A$. cf. aleyrodis inoculation, with peaks of mortality on the tenth day.

KEY WORDS: Biological control, entomopathogenic fungus, citrus pest.

\section{INTRODUÇÃO}

A ocorrência de fungos entomopatogênicos, em condições naturais, tanto enzoótica como epizooticamente, tem sido importantena reduçãodas populações de pragas em agroecossistemas (ALves, 1998). Em áreas de clima tropical, epizootias naturais de Aschersonia spp., Isaria spp., Lecanicillium spp.,

${ }^{2}$ Universidade de São Paulo, Escola Superior de Agricultura Luiz de Queiroz, Departamento de Entomologia, Fitopatologia e Zoologia Agrícola, Piracicaba, SP, Brasil.

${ }^{3}$ Instituto Agronômico, Campinas, SP, Brasil.

${ }^{4}$ USDA-ARS Biological Integrated Pest Management Research Unit - Robert W. Holley Center for Agriculture and Health, Ithaca, NY, USA. 
Hirsutella spp., Paecilomyces spp., Nomuraea rileyi, Syngliocladium sp., Metarhizium anisopliae, Beauveria bassiana, Cordyceps spp., e de muitas espécies de fungos da ordem Entomophthorales são frequentes. Assim, é provável que na América Latina, para cada praga, haja no mínimo um patógeno capaz de exercer o seu controle sustentável (AlvEs et al., 2008).

A grande variabilidade genética desses entomopatógenos pode ser considerada uma das principais vantagens do controle microbiano de insetos (ALVES, 1998). A seleção de isolados adaptados às condições climáticas e de cultivo em cada região é um aspecto importantepara osucesso do programa; exemplos dessa busca podem ser observados nos programas de controle das cigarrinhas da cana-de-açúcar com isolados selecionados de M. anisopliae no Brasil e de pragas em batata com Beauveria brongniartii nas regiões mais frias do Peru e da Bolívia (Alves et al., 2008).

Cerca de $80 \%$ das doenças de insetos têm como agentes etiológicos fungos pertencentes a 90 gêneros que reúnem 700 espécies distribuídas em diferentes grupos taxonômicos (Alves, 1998).

Segundo FRANCESCHINI et al. (2001), os produtos químicos têm efeito negativo sobreo solo, clima, vegetação, água, animais e homem, além de provocar a seleção de indivíduos resistentes. Nesse contexto, o controle biológico é uma alternativa viável para o combate depragas e patógenos evantajosa em relação ao controle químico, especialmente quanto ao impacto ambiental, custo, especificidade e ao desenvolvimento de resistência.

Complementando a ação dos parasitoides e predadores, os patógenos podem ser utilizados como importantes inimigos naturais de aleirodídeos (RAMOS, 2001). Os insetos hospedeiros de Aschersonia sp. estão restritos às famílias Aleyrodidae e Coccidae, na ordem Hemiptera (РетсH, 1921; Evans, 1990; MeEKes et al., 2002 APUD LIU et al., 2006).

A mosca-negra-dos-citros, Aleurocanthuswoglumi, é uma importante praga dos citros (DIETZ; ZETEK, 1920). Apresenta aparelho bucal sugador labial e tanto os adultos como as formas imaturas causam danos ao se alimentarem do floema da planta. As plantas ficam debilitadas, levando ao murchamento e, na maioria das vezes à morte (OliverRA et al., 2001). Durante a alimentação, eliminam uma excreção açucarada na superfície da folha, facilitando o aparecimento da fumagina (Capnodium sp.). A presença desse fungo reduz a fotossíntese, impede a respiração (NGUYEN;HAMON, 2003) ediminui onível denitrogênio nas folhas. O ataque dessa praga pode levar a perdas de $80 \%$ na frutificação (OlIVEIRA et al., 2001).

$\mathrm{O}$ controle biológico da mosca-negra-dos-citros tem sido mais eficiente que o controle químico em diversas partes do mundo, sendo realizado por meio de parasitoides, predadores e do fungo entomopa- togênico Aschersonia aleyrodis (OliveIra et al., 2001). $\mathrm{Na}$ Costa Rica, o uso de parasitoides e predadores juntamentecom A. aleyrodis foi eficientenocontrole da mosca-negra (OliveIra et al., 2001).

O presente trabalho teve por objetivo avaliar o efeito de Aschersonia cf. aleyrodis in vitro nos diferentes estádios dedesenvolvimentodeAleurocanthuswoglumi, como potencial agente de controle biológico, através de testes com diferentes concentrações de inóculo do fungo.

\section{MATERIALEMÉTODOS}

\section{Criação-estoque}

Os insetos utilizados nos bioensaios foram obtidos da criação-estoque, localizada noSetor deProdução da Faculdade de Ciências Agrárias da UniversidadeFederal do Amazonas FCA/UFAM. Foi utilizada a lima ácida Tahiti (limão Tahiti) Citrus latifolia (Yu.Tanaka) Tanaka, porta-enxertoCleópatra, por ter sidoeste o melhor hospedeironos estudos da biologia da mosca-negra-dos-citros (PenA; SIlva, 2007; Pena et al., 2009).

Obtenção e isolamento do fungo Aschersonia cf. aleyrodis

Foram coletadas folhas de laranja, Citrus sinensis (L.) Osbeck no setor de produção da FCA/UFAM, ondehavia ninfas de mosca-negra mortas associadas ao fungo (Fig. 1A). Fragmentos de colônias de $A$. cf. aleyrodis presentes nas folhas foram submetidos a uma desinfestação superficial nas soluções de álcool $70 \%$, hipoclorito $2 \%$ e lavados em água destilada. Em seguida, estes fragmentos foram postos para secar em papel toalha. Após secagem, foram depositados em placas dePetricontendo meio de cultura BDA [batata, 200 g; dextrose, 20 g; ágar, 20 g; água destilada, $1 \mathrm{~L} \mathrm{e}$ Cloranfenicol (250 mg/L de BDA)] e colocados em incubadora BOD (Biological Oxygen Demand), à temperatura de $27 \pm 2^{\circ} \mathrm{C}$, até a produção de esporos.

Após o isolamento de $A$. cf. aleyrodis, o fungo foi repicado para placas de Petri com BDA, que foram colocadas em prateleiras, fora da BOD, na presença de luz fluorescente contínua durante 30 dias para estimularocrescimentoe a produção de esporos(Fig.1B). Os isolados do fungo foram preservados em tubos de ensaio contendo meio de cultura BDA eóleo mineral, armazenados em $\mathrm{BOD} \mathrm{a} 18^{\circ} \mathrm{C}$. Estes foram depositados na Coleção do Lab. de Microbiologia da FCA/ UFAM e do USDA-ARS Biological Integrated Pest Management ResearchUnit-RobertW.HolleyCenter for Agriculture and Health e identificado pelo oitavo autor. 


\section{Preparação da suspensão dos conídios}

Para a preparação da suspensão de conídios, foram adicionados $40 \mathrm{~mL}$ de água destilada esterilizada nas placas contendo colônias do fungo. Os esporos foram removidos com o auxílio de um pincel de cerdas macias. A solução foi recolhida em um béquer, onde foram adicionados $10 \mu \mathrm{L}$ de Tween $80^{\circledR}$. A concentração foi ajustada utilizando-se câmara de Newbauer (RAmos, 2001). As concentrações foram ajustadas de acordo com o objetivo do bioensaio. Para avaliação do efeito de diferentes concentrações de inóculo de Aschersonia cf. aleyrodis sobre ninfas de $A$. woglumi foram usadas: $0 ; 2,3 \mathrm{x}$ $10^{4} ; 2,3 \times 10^{6} ; 2,3 \times 10^{7}$ e $2,3 \times 10^{8}$ conídios $/ \mathrm{mL}$, inoculados em ninfas de $3^{\circ}$ ínstar. Para avaliação do efeito de $A$. cf. aleyrodis, nas diferentes fases de desenvolvimento de $A$. woglumi, foi selecionada a concentração de $3,9 \times 10^{7}$ conídios $/ \mathrm{mL}$, concentração que ocasionou maior mortalidade no bioensaio anterior, inoculados nas fases de ovo e ninfas de $1^{\circ}$, $2^{\circ}, 3^{\circ}$ e $4^{\circ}$ ínstar.

Aplicação de $A$. cf. aleyrodis em diferentes fases de desenvolvimento de $A$. woglumi

Para os bioensaios foram usadas folhas de lima ácida Tahiti infestadas com ovos ou ninfas $\left(1^{\circ}, 2^{\circ}\right.$, $3^{\circ}$ e $4^{\circ}$ instar) de mosca-negra-dos-citros, de acordo com o objetivo do bioensaio. Em cada folha, vinte ovos ou ninfas foram selecionadas ao acaso, sendo o excesso eliminado com auxílio de um estilete. As regiões contendo os insetos foram demarcadas com caneta de retroprojetor de ponta de $1 \mathrm{~mm}$, para facilitar o registro e controle dos dados. O pecíolo foi envolvido em algodão umedecido com água destilada, o qual foi trocado diariamente, para evitar o ressecamento precoce do material vegetal.

Os testes foram realizados em placas de Petri contendo uma camada de papel filtro circular esterilizado, onde foi colocada uma folha de citros por placa. Com auxílio de um microaspersor, a inoculação foi feita adicionando-se $3 \mathrm{~mL}$ de suspensão de conídios nas diferentes concentrações em cada placa. Em seguida, as placas foram cobertas com filme plástico perfurado e incubadas em $\mathrm{BOD}\left(25 \pm 1^{\circ} \mathrm{C}\right.$ e $86,1 \pm 2 \%$ e fotofase de 12 horas). As avaliações foram feitas diariamente, até o $19^{\circ}$ dia após a inoculação, registrando-se a mortalidade de ninfas em cada folha.

Para a confirmação da morte das ninfas pelo patógeno, foi feito o reisolamento do fungo a partir das ninfas mortas, as quais foram lavadas em álcool 70\%, colocadas em papel filtro esterilizado e, posteriormente, transferidas para placas de Petri contendoágar-água (1,5\%), conforme metodologia utilizada por RAMOS (2001) e TAMAI (2002). As placas foram mantidas em BOD com temperaturas de $27 \pm 2{ }^{\circ} \mathrm{C}$.

\section{Análise dos dados}

No bioensaio para avaliação das diferentes concentrações de inóculo de $A$. cf. aleyrodis em ninfas de $A$. woglumi, adotou-se o delineamento inteiramente casualizado com cinco tratamentos (concentrações) e três repetições, sendo cada repetição representada por 20 ninfas por placa. No bioensaio para avaliação do efeito de $A$. cf.aleyrodis, em diferentes fases de desenvolvimento de $A$. woglumi, foi utilizado um delineamento inteiramente casualizado com cinco tratamentos (fases de desenvolvimento) e quatro repetições, sendo cada repetição representada por 20 ninfas ou ovos por placa.

Os dados (mortalidades totais) foram submetidos à análise de variância e, posteriormente, ao teste de Tukey $(p<5 \%)$. Para o segundo experimento, a mortalidade foi corrigida, utilizando a fórmula de Аввотт (1925). Foi utilizado o programa Statistica 6.0 na análise dos dados.

A análise de Probit foi realizada utilizando o programa Polo-PC para os cálculos da Concentração Letal Mediana $\left(\mathrm{CL}_{50}\right)$ e Tempo Letal Mediano $\left(\mathrm{TL}_{50}\right)$.

\section{RESULTADOSEDISCUSSÃO}

\section{Ocorrência de $A$. cf. aleyrodis em campo}

Em observações de campo foi verificado o crescimento maciço de $A$. cf. aleyrodis associados à moscanegra-dos-citros em folhas de laranja e tangerina causando a morte deste inseto. Estas folhas foram levadas ao Laboratório de Entomologia Agrícola e examinadas ao microscópio estereoscópico.

\section{Crescimento de $A$. cf. aleyrodis em BDA.}

Após o isolamento do fungo, $A$. cf. aleyrodis, este foi repicado em placas de Petri com BDA, sendo verificado seu lento crescimento. Aos trinta e dois dias de idade as colônias apresentaram em média $3,92 \pm 0,33(3,30-4,70) \mathrm{cm}$ de diâmetro. A partir deste período não foi observado aumento no tamanho das colônias, e teve início um processo de descoloração, perdendo o tom alaranjado intenso. Esses dados corroboram com os relatos da literatura, onde mencionam que as espécies de Aschersonia crescem lentamente em cultura (RAMAKERS; SAMSOM, 1984 apud LIU et al. 2006). 

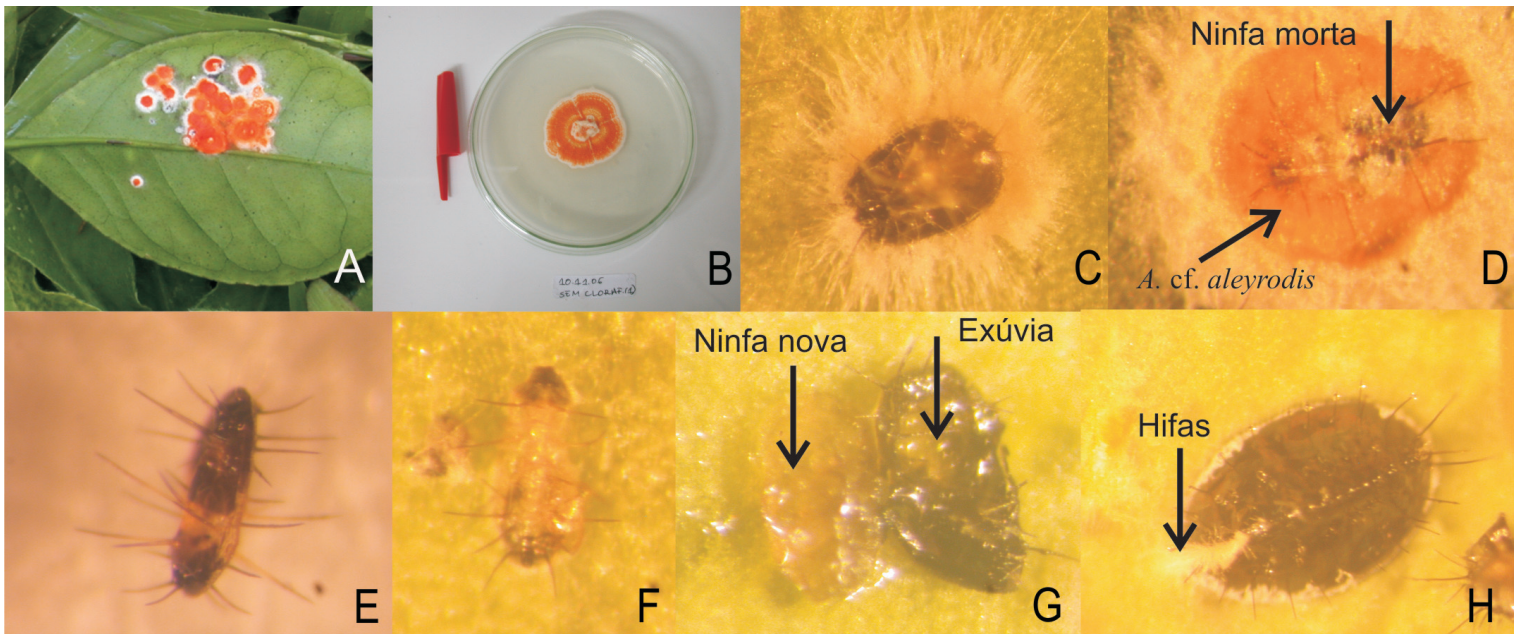

Fig. 1 - A) Colônias de Aschersonia sp. associadas à mosca-negra-dos-citros em campos; B) Crescimento de Aschersonia sp. em BDA;C) Crescimento inicial do fungo sobre ninfa de mosca-negra-dos-citros; D) Crescimento avançado; E) Ninfas de mosca-negra-dos-citros mumificada; F) Ninfas com sintomas de histólise; G) Ninfas novas já contaminadas; H) Emergência de hifas.

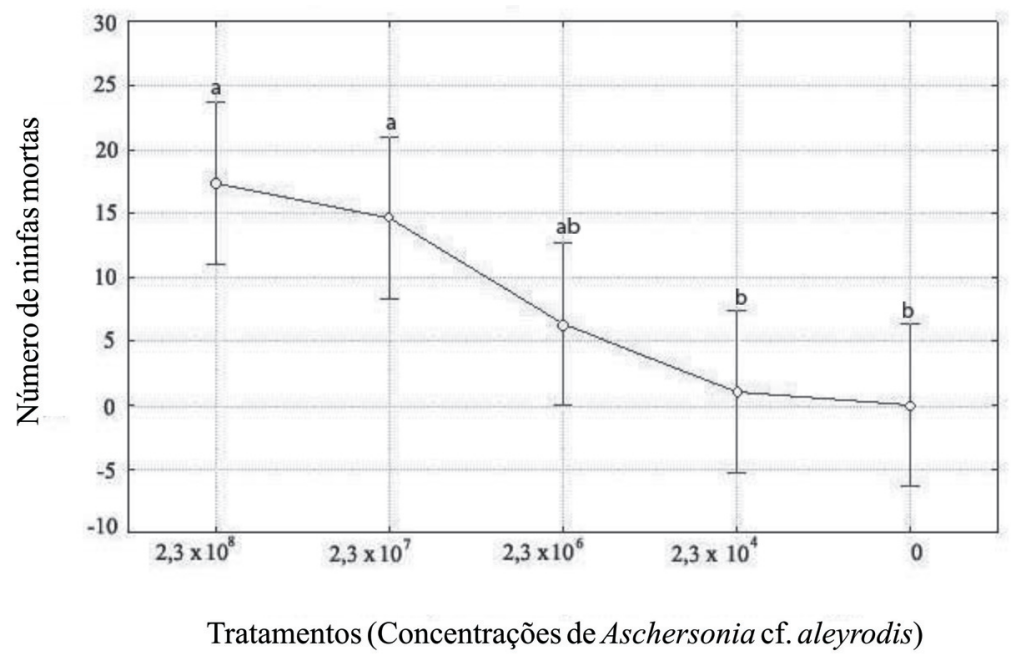

Fig. 2 - Mortalidade de mosca-negra-dos-citros, A. woglumi sob diferentes concetrações de Aschersonia sp. em condiçoes de laboratório.

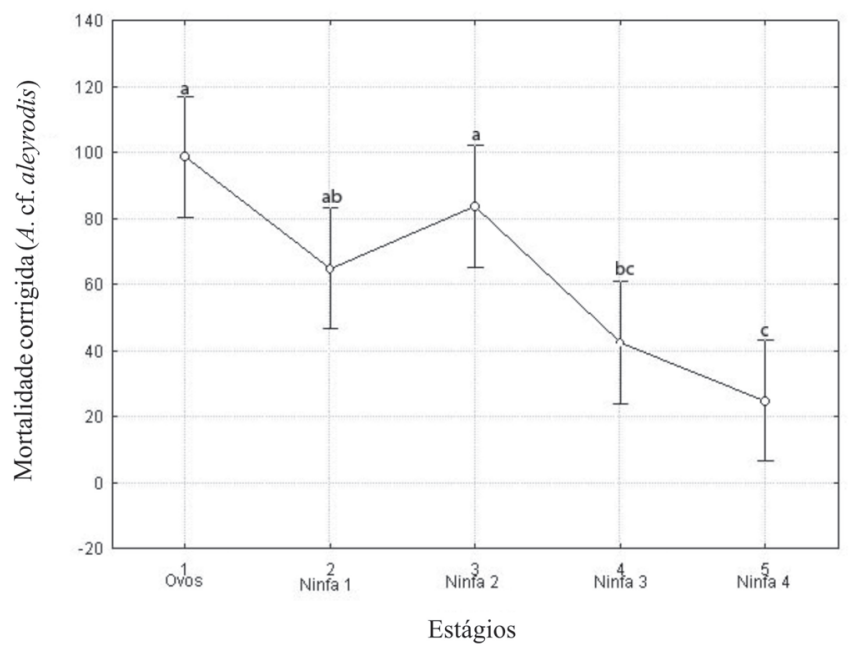

Fig. 3 - Mortalidade corrigida dos estádios imaturos da mosca-negra-dos-citros, A. woglumi pela ação do fungo Aschersonia sp. em condiçoes de laboratório. 
Avaliação do efeito de diferentes concentrações de inóculo de $A$. cf.aleyrodis em ninfas de $A$. woglumi

A maior mortalidade ocorreu nos tratamentos 1 $\left(2,3 \times 10^{8}\right.$ conídios $\left./ \mathrm{mL}\right)$ e $2\left(2,3 \times 10^{7}\right.$ conídios $\left./ \mathrm{mL}\right)$, não havendo diferença entre eles. Estes diferiram dos tratamentos $4 \mathrm{e} 5$ (testemunha). A menor mortalidade ocorreu no tratamento 4 , que não diferiu do tratamento 3 e nem da testemunha, demonstrando o efeito letal do entomopatógeno em concentrações altas (Fig. 2).

$\mathrm{ACL}_{50}$ foide $5,8 \times 10^{6}\left(8,6 \times 10^{5}-3,0 \times 10^{7}\right)$ conídios/ $\mathrm{mL}$. A TL ${ }_{50}$ para a concentração de $2,3 \times 10^{7}$ conídios/ $\mathrm{mL}$ foi de 12,18 $(10,91-13,59)$ dias, já para 2,3 $\times 10^{8}$ conídios $/ \mathrm{mL}$ a $\mathrm{TL}_{50}$ foi de $9,45(8,38$ - 10,49) dias.

$\mathrm{O}$ crescimento do fungo sobre o inseto é inicialmente branco, de aspecto cotonoso, tornando-se posteriormente alaranjado (Figs. 1C e 1D). As ninfas ficam inicialmente mumificadas (Fig. 1E) e/ou com sintomas de histólise (decomposição do tecido por ação enzimática) (Fig. 1F) de cor alaranjado-clara. A ação do fungo pode também impedir a troca completa da exúvia, pigmentando o novo tegumento em tom alaranjado, inviabilizando o desenvolvimento das fases subsequentes (Fig. 1G). Outra forma de ação do fungo ocorre quando o inseto consegue realizar a troca de tegumento, estandonesse caso já contaminado, com posterior emergência das hifas pelas regiões intersegmentais do abdome e orifício vasiforme (Fig. 1H). Segundo Alves; Pereira (1998), a maioria dos fungos é capaz de penetrar via tegumento e, durante esse processo de penetração, causa distúrbios nessa primeira barreira de proteção do corpo dos insetos; assim, o tegumento torna-se bastante vulnerável à penetração de patógenos por ocasião da mudança de ínstares, quando o novo tegumento formado ainda não está esclerotizado.

Quando completamente desenvolvido, o fungo cobre as ninfas, adquirindo a coloração característica de um alaranjado intenso, podendo crescer e atingir as ninfas vizinhas.

Não foi possível realizar o reisolamento de $A$. cf. aleyrodis a partir das ninfas mortas para o cálculo de mortalidade confirmada, devido ao surgimento de fungos contaminantes que cresciam mais rapidamente nas placas, desfavorecendo o desenvolvimento de A. cf. aleyrodis. Segundo TAmai (2002), o fato de alguns ácaros não apresentarem esporulação do entomopatógeno não descarta totalmente a possibilidade de terem sido mortos pelo inimigo natural. Para este autor em alguns casos, o álcool utilizado na desinfestação externa pode inviabilizar o fungo após a sua entrada para o interior do cadáver por eventuais fissuras no tegumento, provocadas pelo manuseio, além da ação rápida de bactérias decompositoras no cadáver podendo impedir que o fungo esporule.
Avaliação do efeito de $A$. cf. aleyrodis em diferentes fases de desenvolvimento de $A$. woglumi

As maiores mortalidades corrigidas ocorreram nas fases de ovo, ninfa 2 e ninfa 1 , não havendo diferença entre elas (Fig. 3). Mortalidades elevadas $(90 \%)$ em ninfas da mosca-branca Dialeurodes citripor A. placenta foram verificadas por FERRON (1978) apud Alves (1998). Outros autores também relataram mortalidades elevadas em ninfas de moscas-brancas (MEeKES et al., 2000; MEeKEs et al., 2002) quando tratadas com Aschersonia sp.

Estudos da suscetibilidade de Trialeurodes vaporariorum à infecção por A. aleyrodis mostram que cerca de $90 \%$ dos ovos, ninfas de primeiro e segundo ínstar foram infectadas quando tratadas com $2 \mathrm{ml}$ de uma suspensão de $4 \times 10^{6}$ conídios $/ \mathrm{mL}$. A percentagem de infecção sobre o terceiro e quarto ínstar alcançou 76 e $28 \%$, respectivamente (FRANSEN., 1987, apud RAMOS, 2001).

Após a aplicação da suspensão de conídios, os ovos inviáveis adquiriram coloração marrom-escura e ficaram "murchos" (desidratados) eretorcidos, contrastando com os ovos nas testemunhas que possuíam coloração alaranjada e se mantiveram túrgidos e brilhantes. Os ovos submetidos à aplicação deconídios apresentavam a linha de eclosão, sendo perceptívelo corpo da ninfa, mas sem haver eclosão desta. As ninfas ficaram inicialmente mumificadas e/ou com sintomas de histólise.

No estádio de ninfa 4 ocorreu a menor taxa de mortalidade corrigida, apesar de não diferir da taxa constatada com a ninfa 3. Estes dados corroboram os trabalhos de SENGONCA et al. (2006), que, embora trabalhando com outra ordem de inseto, avaliaram 41 isolados de fungos entomopa-togênicos, sendo 14 altamente patogênicos a tripes (Thysanoptera: Thripidae) e verificaram que a suscetibilidade dos estágios de desenvolvimento ao fungo entomopatogênico decaiu da larva para pupa e desta para os adultos. A menor mortalidade no estádio de ninfa 4 pode ter sido em razão da maior dificuldade de o fungo penetrar no tegumento do inseto, pois foi verificado que estas ninfas possuem o tegumento mais esclerotizado em relação às demais fases de desenvolvimento.

Espécies de Aschersonia contaminam tanto moscas-brancas como cochonilhas presumivelmente pela germinação e penetração direta do conídio aderido à cutícula do hospedeiro (MeEKes et al., 2002).

As mortalidades nas fases de ovo, ninfas 1, 2, e 3, com exceção da ninfa 4 , iniciaram-se no quarto dia após a inoculação de $A$. cf. aleyrodis evariaram de 1,2\% a $5 \%$ nas referidas fases. Esta baixa mortalidade inicial corrobora os estudos de TAMAI et al. (2002), em 
que a mortalidade do ácaro Tetranychus urticae por Aschersonia sp. no $5^{\circ}$ dia foi inferior a 3\%.

$\mathrm{Na}$ fase de ovo, os acmes de mortalidades ocorreram no $10^{\circ}(36,2 \%)$ e $11^{\circ}(17,5 \%)$ dia; para ninfa 1 , no $10^{\circ}(25 \%)$ e $17^{\circ}(17,5 \%)$ dia; para ninfa 2, no $10^{\circ}(23,7 \%)$ e $12^{\circ}(18,7 \%)$ dia; para ninfa 3 , no $10^{\circ}(13,7 \%)$ dia. Na fase de ninfa 4 , a mortalidade teve início no $10^{\circ}$ dia com acme no $11^{\circ}(10 \%)$ dia. Os acmes de mortalidade ocorridos comouso de A.cf. aleyrodis nesteestudo (em média no $10^{\circ}$ dia para as diferentes fases) foram tardios quando comparados com Beauveria spp., $M$. anisopliae e Hirsutella sp. Para esses fungos os valores de mortalidade corrigida tornam-se maiores a partir do terceiro dia, sendo o acme de mortalidade no quarto e quinto dia após a inoculação dos isolados;no quinto dia, a mortalidade ficou entre 70 e $80 \%$ (TAMAI et al., 2002).

Nas fases de ovo e das ninfas 1, 2, 3 e 4, as mortalidades corrigidas no $19^{\circ}$ dia foram de $98 \%$; $65 \% ; 83,7 \% ; 42,5 \%$ e $25 \%$, respectivamente.

Segundo TAmai et al. (2002), a rapidez com que o patógeno mata seu hospedeiro é uma característica desejável para o controle de muitas pragas agrícolas, contudo não deve ser considerada como única. É imprescindível também que o isolado seja capaz de proporcionar elevada mortalidade final, possibilitando, desse modo, pulverizações menos frequentes e, consequentemente, redução dos custos de controle de pragas.

$\mathrm{Na}$ literatura estão relacionadas espécies de Aschersonia controlando aleirodídeos (Alves, 1998; LOURENÇÃo et al., 1999; ROJAs, 2000; MEEKEs et al., 2000; MeEKes et al., 2002; Liu et al., 2006). No Brasil, a ocorrência de Aschersonia sp. em mosca-branca é muito comum, aparecendo em todas as regiões onde se cultivam citros (Alves, 1998).

A ocorrência natural deste fungo nos plantios de citros no Amazonas, colonizando e causando a mortalidade da mosca-negra, além dos bioensaios realizados em laboratório, demonstra uma alternativa viável no controle dessa praga, como importante instrumento no âmbito do manejo integrado de pragas. Há boa possibilidade de multiplicação e uso de entomopatógenos adaptados às condições climáticas da região amazônica.

A. aleyrodiséeficientenocontrolede $A$.woglumi, em diversas partes do mundo (OliveIRA et al., 1999). A região amazônica possui as condições ideais de umidade e temperatura para o crescimento e esporulação desse fungo, havendo necessidade de mais estudos objetivando testar seu desempenho em todas as fases do ciclo evolutivo do inseto, seleção de meios de crescimento menos onerosos, multiplicação, além da avaliação do impacto sobre parasitoides e predadores da mosca-negra.

\section{CONCLUSÃO}

Aschersonia cf. aleyrodis é eficiente no controle da mosca-negra-dos-citros, em laboratório, em concentrações a partir de 2,3 $\times 10^{7}$ conídios $/ \mathrm{mL}$.

$\mathrm{ACL}_{50}$ foi de $5,8 \times 10^{6}\left(8,6 \times 10^{5}-3,0 \times 10^{7}\right)$ conídios/ mL. A TL ${ }_{50}$ para a concentração de $2,3 \times 10^{7}$ conídios / $\mathrm{mL}$ foi de $12,18(10,91-13,59)$ dias, já para $2,3 \times 10^{8}$ conídios $/ \mathrm{ml} \mathrm{TL}_{50}$ foi de $9,45(8,38$ - 10,49) dias.

As maiores mortalidades com o uso de $A$. cf. aleyrodis ocorrem nas fases mais jovens de $A$. woglumi como ovo, ninfa 2 e ninfa 1 . No estádio de ninfa 4 ocorre a menor mortalidade.

As mortalidades nas fases de ovo, ninfas $1,2 \mathrm{e}$ 3 iniciam-se no quarto dia após a inoculação de $A$. cf. aleyrodis com acmes de mortalidade no décimo dia.

\section{AGRADECIMENTOS}

Ao CNPQ e CAPES (PROCAD) pelo apoio financeiro. Ao professor José Odair Pereira da Universidade Federal do Amazonas UFAM, Geraldo Vasconcelos e Raquel Corrêa pelas sugestões. Ao Rafael Major Pitta pela ajuda na análise de Probit.

\section{REFERENNCIAS}

ABBOTT, W.S. A method of computing the effectiveness of an insecticide. Journal of Economic Entomology, v.18, p.265-267, 1925.

ALVES, S.B. Fungos entomopatogênicos. In: (Ed.). Controle microbiano de insetos. Piracicaba: FEALQ, 1998. p.289-381.

ALVES, S.B.; PEREIRA, R.M. Distúrbios fisiológicos provocados por entomopatógenos. In: ALVES, S.B. (Ed.). Controle microbiano de insetos. Piracicaba: FEALQ, 1998. Cap. 2, p.39-52.

ALVES, S.B.; LOPES, R.B.; PEREIRA, R.M.; TAMAI, M.A. $\mathrm{O}$ controle microbiano na América Latina. In: ALVES, S.B.; LOPES, R.B. (Ed.). Controle microbiano de pragas na América Latina. Piracicaba: FEALQ, 2008. Cap.1, p.21-48.

EVANS, H.C.; YWELL-JONES, N. Aspects of the genera Hypocrella and Aschersonia as pathogens of coccids and whiteflies. In: INTERNATIONAL COLLOQUIUM ON INVERTEBRATE PATHOLOGY AND MICROBIAL CONTROL, 5., 1990, Adelaide. Proceedings. Adelaide: Society for Invertebrate Pathology, 1990. p.111-115.

FERRON, P. Biological control of insect pests by entomogenous fungi. Annual Review of Entomology, v.23, p.409-442, 1978. 
FRANCESCHINI, M.; GUIMARÃES, A.P.; CAMASSOLA, M.; FRAZZON, A.P.; BARATTO, C.M.; KOGLER, V.; SILVA, M.V.; DUTRA, V.; NAKAZOTO, L.; CASTRO, L.; SANTI, L.; VAINSTEIN, M.H.; SCHRANK, A. Biotecnologia aplicada ao controle biológico. Revista Biotecnologia Ciência e Desenvolvimento, n.23, p.32-37, 2001.

FRANSEN, J.J. Aschersonia aleyrodis as a microbial control agent of greenhouse whitefly. 167p. 1987. PhD (Thesis Poonsen en Looijen) - Wageningen Agricultural University, Wageningen, 1987.

LIU, M.; CHAVERRI, P.; HODGE, K. A taxonomic revision of the insect biocontrol fungus Aschersonia, its allies with whrite stromata and their Hypocrella sexual states. Mycological Research, v.110, n.5., p.537-554, 2006.

LOURENÇÃO, A.L.; YUKI, V.A.; ALVES, S.B. Epizootia de Aschersonia cf goldiana em Bemisia tabaci (Homoptera: Aleyrodidae) biótipo B no Estado de São Paulo. Anais da Sociedade Entomológica do Brasil, v.28, n.2, p.343-345, 1999.

MEEKS, E.T.M.; VAN-VOORST, S.; JOOSTEN, N.N.; FRANSEN, J.J.; VAN-LENTEREN, J.C. Persistence of the fungal whitefly pathogen, Aschersonia aleyrodis, on three different plant species. Mycological Research, v.104, n.10, p.1234-1240, 2000.

MEEKES, E.T.M.; FRANSEN, J.J.; VAN- LENTEREN, J.C. Pathogenicity of Aschersonia spp. against whiteflies Bemisia argentifolii and Trialeurodes vaporariorum. Journal of Invertebrate Pathology, v.81, n.1, p.1-11, 2002.

NGUYEN, R.; HAMON, A.B. Citrus blackfly, Aleurocanthus woglumi Ashby (Homoptera: Aleyrodidae). Gainesville: University of Florida, 2003. (CIR 360).

OLIVEIRA, M.R.V.; SILVA, C.C.A.; NÁVIA, D. (Ed.). Praga quarentenária 1. A mosca negra dos citros, Aleurocanthus woglumi Ashby (Hemiptera: Aleyrodidae). Brasília: Ministério da Agricultura, Pecuária e Abastecimento, 1999. 7p.

OLIVEIRA, M.R.V.; SILVA, C.C.A.; NÁVIA, D. (Ed.). Mosca negra dos citros Aleurocanthus woglumi: Alerta quarentenário. Brasília: Ministério da Agricultura, Pecuária e Abastecimento, 2001. 12p.

PENA, M.R.; SILVA, N.M. Sugadora negra. Revista Cultivar: Hortaliças e Frutas, v.7, n.41, p.16-18, 2007.

PENA, M.R.; SILVA, N.M.; VENDRAMIM, J.D.; LOURENÇÃO, A.L.; HADDAD, M.L. Biologia da moscanegra-dos-Citros, Aleurocanthus woglumi Ashby (Hemiptera: Aleyrodidae) em três Plantas hospedeiras. Londrina/PR. Neotropical Entomology, v.38, p.254-261, 2009.

PETCH, T. Studies in entomogenous fungi. II. The genera Hypocrella and Aschersonia. Annals of the Royal Botanic Gardens Peradeniya, v.7, p.167-278, 1921.

RAMAKERS, P.M.J.; SAMSON, R.A. Aschersonia aleyrodis, a fungal pathogen of whitefly. II. Application as a biological insecticide in glasshouses. Zeitschrift für angewandte Entomologie, v.97, p.1-8, 1984.

RAMOS, E.Q. Seleção de isolados de fungos entomopatogênicos para o controle de Bemisia tabaci biótipo B. 2001. 57f. Dissertação (Mestrado em Ciências, área de concentração: Entomologia) - Universidade de São Paulo, Escola Superior de Agricultura "Luiz de Queiroz" , Piracicaba, São Paulo, 2001.

ROJAS, T. Aschersonia basicystis sobre insectos escamas (Homoptera: Coccidae) en Venezuela. Revista Iberoamericana Micología, v.17, p.134-137, 2000.

SENGONCA, C.; THUNGRABEAD, M.; BLAESER, P. Potential of different isolates of entomopathogenic fungi from Thailand as biological control agents against western flower thrips, Frankliniella occidentalis (Pergande) (Thysanoptera: Thripidae). Journal of Plant Diseases and Protection, v.113, n.2, p.74-80, 2006.

TAMAI, M.A.; ALVES, S.B.; ALMEIDA, J.E.M DE.; FAION, M. Avaliação de fungos entomopatogênicos para o controle de Tetranychus urticae Koch (Acari: Tetranychidae). Arquivos do Instituto Biológico, São Paulo, v.69, n.3, p.77-84, 2002.

Recebido em 18/12/08

Aceito em 9/10/09 